\title{
Australia-Modified Karnofsky Performance Status 30
}

National Cancer Institute

\section{Source}

National Cancer Institute. Australia-Modified Karnofsky Performance Status 30. NCI

Thesaurus. Code C107491.

Almost completely bedfast. 